\title{
HPLC determination of perfluorinated carboxylic acids with fluorescence detection
}

\author{
Ewa Poboży • Edyta Król • Lena Wójcik • \\ Mariusz Wachowicz $\cdot$ Marek Trojanowicz
}

Received: 2 September 2010 / Accepted: 18 November 2010 /Published online: 12 December 2010

(C) The Author(s) 2010. This article is published with open access at Springerlink.com

\begin{abstract}
Perfluorinated carboxylic acids (PFCAs) represent an important group of persistent perfluorinated organic compounds commonly determined in environmental and biological samples. A reversed-phase HPLC method was developed based on derivatization of the PFCAs with the commercially available fluorescent reagent 3-bromoacetyl coumarin. The method was optimized and this resulted in the efficient separation of PFCAs containing from 3 to 12 carbon atoms in molecule in $25 \mathrm{~min}$ run. To improve sensitivity, the preconcentration step has been optimized using Oasis-WAX and C18 sorbents for SPE. A 100-fold preconcentration is achieved by solid-phase extraction with the sorbent C18 Sep-PAK to result in limits of detection in the range from 43 to $75 \mathrm{ppt}$ for the analytes examined, and in the application of the method of water analysis.
\end{abstract}

Keywords Perfluorinated carboxylic acids · HPLC .

Fluorescence detection

\section{Introduction}

Perfluorinated compounds (PFCs) are a family of fluorinecontaining compounds with a fully fluorinated carbon chains.

E. Poboży • E. Król • L. Wójcik • M. Wachowicz •

M. Trojanowicz $(\bowtie)$

Department of Chemistry, University of Warsaw,

Pasteura 1,

PL 02-093 Warsaw, Poland

e-mail: trojan@chem.uw.edu.pl

\section{Trojanowicz}

Laboratory of Nuclear Analytical Techniques, Institute of Nuclear Chemistry and Technology,

Dorodna 16 ,

03-185 Warsaw, Poland
Due to their unique properties such as resistance to high temperature, capacity to form water, stain, oil and grease repellent surface, they have found many applications [1]. In spite of introduction of PFCs in 1950s, the identification and quantification have been possible since late 1990-ties when analytical methods of sufficient sensitivity were available. The widespread occurrence of certain perfluorinated compounds in the environment, in animal as well as in human species, has attracted great attention in last years. Significant levels of PFCs were detected in various environmental samples and they are considered as new class of persistent organic pollutants [2].

Among different PFCs, the increasing of occurrence of perfluorinated carboxylic acids (PFCAs) in last decade has been reported in the environment in many countries. They are released into the environment by manufacturing processes, during production of fluoropolymers, and as residuals from products, or by degradation processes of other fluorinated compounds.

Global widespread of PFCAs is observed and they have been identified as well in environmental samples [3], as in animal tissues [4], and human blood [5]. The sources, fate and transport of PFCAs, with a specific focus on perfluorooctanoic acid (PFOA) in the environment (ocean water, freshwater, sediments and air) have been recently thoroughly reviewed [6]. Also extensive studies of PFOA toxicity for living organisms and human exposure sources have been carried out [7].

Determination of PFCAs in low trace level is an analytical challenge. Reliable methods of extraction, separation and identification in complex matrixes are necessary. The difficulty of the determination of PFCAs is very low concentration in the samples (ng-pg $\mathrm{L}^{-1}$ or ng-pg $\mathrm{g}^{-1}$ ) and their weak absorption in UV. A few analytical methods have been developed to determine PFCAs and most commonly employed are chromatographic ones [8].

For determination of PFCAs without derivatization, the liquid chromatography with the MS/MS detection and 
electrospray ionization is commonly used for analysis of environmental [9-11] and biological samples [12-14]. Ion chromatography with conducto metric detection for separation PFCAs having $\mathrm{C} 3-8$ has been also presented [15], with LODs in range $0.12-0.66 \mathrm{mg} \mathrm{L}^{-1}$, while with SPE preconcentration the limit of detection of $50 \mu \mathrm{g} \mathrm{L}^{-1}$ was reported.

Different approaches using solid-phase extraction methodology for preconcentration of PFCAs have been developed. For determination with LC-MS, the methodology of Moody et al. [16] employing C18 sorbents has been mainly employed by various authors, which is limited to long chain acids. Recently, also application of polymeric sorbents Oasis HLB and Oasis WAX mixed-mode weak anion-exchange reversed phase for PFCAs preconcentration has been presented [9, 17]. The acceptable recoveries of PFOA using both $\mathrm{C} 18$ (124\%) and Oasis HLB (147\%) were obtained but the lower background levels were observed for Oasis HLB cartridges [9]. Recovery of PFOA from water samples using Oasis HLB ranged from 33 to $98 \%$, and it was above $50 \%$ for $80 \%$ of the samples analyzed, as reported by MacLachlan et al. [30].

For HPLC analysis of PFCAs with the fluorimetric detection Ohya et al. [18] reported derivatization with laboratory synthesized 3-bromoacetyl-7-methoxycoumarin (BrAMC), and conditions of carrying out reaction and separation were optimized for analysis of tissues. The developed method was applied for determination of PFCAs in rats liver and recoveries $>90 \%$ were obtained for $50 \mathrm{mg}$ homogenate spiked with $1 \mathrm{nM}$ PFCAs. This method was also employed to study transport of PFCAs in organisms and their elimination [19], and to study toxicity of determined analytes [20].

The aim of this work was to develop the HPLC method for determination of perfluorinated carboxylic acids with fluorimetric detection based on the use of commercially available fluorophores and to develop the procedure for analysis of natural water samples. For investigation, PFCAs with 2 to 12 carbon atoms were chosen, which occur most commonly in environmental samples. The studies were focused on investigation of two coumarin fluorophores, namely 3-bromoacetylcoumarin (3-BrAC) and 4-bromomethyl-7-methoxycoumarin (BrMMC), which are commercially available, and the latter one was already employed for derivatization of carboxylic acids for HPLC determination with fluorimetric detection of fatty acids $[21,22]$, okadaic acid and other shellfish poisoning toxins [23], and monofluoroacetate [24].

\section{Experimental}

Materials and chemicals

The following perfluorinated carboxylic acids (PFCAs) were purchased from Aldrich (Milwaukee, USA, www. sigmaaldrich.com): perfluoroacetic acid (abbreviated as $\mathrm{C} 2$ ), perfluoropropionic acid (C3), perfluorobutyric acid (C4), perfluoropentanoic acid (C5), perfluorohexanoic acid (C6), perfluoroheptanoic acid (C7), perfluorooctanoic acid (C8 or PFOA), perfluorononanoic acid (C9), perfluorodecanoic acid (C10), perfluoroundecanoic acid (C11), and perfluorodode canoic acid (C12). Puritiy of all reagents was better than $95 \%$. Methanol and acetonitrile (ACN), both of chromatographic purity, were obtained from Merck (Darmstadt, Germany, www.merck.com). Ammonium solution (25\%), acetone and sodium hydroxide were from Chempur (Piekary Slaskie, Poland, www.chempur.pl). 4-bromo-methyl-7-methoxycoumarin (BrMMC) and 3bromoacetyl-coumarin (3-BrAC) were purchased from Aldrich (Milwaukee, USA). Mili-Q (Millipore, USA) water was used throughout the all experiments.

Stock standard solutions of PFCAs of concentration $1,000 \mathrm{mg} \mathrm{L}^{-1}$ were prepared by dissolving them in acetonitrile. These solutions were stored in the dark at $4{ }^{\circ} \mathrm{C}$. A series of working standards solutions were prepared by subsequent dilution of stock solutions with acetonitrile to reach concentrations range $0.025-0.5 \mathrm{mg} \mathrm{L}^{-1}$. The standard mixtures for precon centration studies were obtained by dilution and mixing of stock solutions with water.

Solutions of coumarin derivatives $\left(2.0\right.$ or $\left.5.0 \mathrm{gL}^{-1}\right)$ were prepared by dissolving appropriate amount of solid reagent in acetone. 3-BrAC dissolves easy in acetone but BrMMC needs long time dissolving in ultrasonic bath. The solutions were stored in the dark at $4{ }^{\circ} \mathrm{C}$.

\section{Instrumentation}

The HPLC system Merck-Hitachi (Darmstadt, Germany) consisted of a system controller D-7000, an autosampler L7250 (with sample volume loop $50 \mu \mathrm{L}$ ), a degasser, a gradient pump L-7100 and fluorescence detector L-7485. The detector was set at an excitation wavelength $306 \mathrm{~nm}$ and emission wavelength $420 \mathrm{~nm}$ for the derivatization with $\mathrm{BrAC}$ and at an excitation wavelength $330 \mathrm{~nm}$ and emission wavelength $390 \mathrm{~nm}$ for the derivatization with BrMMC. The analytical column was Phenomenex (Torrance, USA, www. phenomenex.com) Synersi C18 $(4 \mu \mathrm{m}), 150 \times 4.6 \mathrm{~mm}$ I.D. Gradient elution with flow rate $1 \mathrm{~mL} \mathrm{~min}{ }^{-1}$ was applied for separation. The gradient was hold at $100 \%$ eluent A for 5 min, then operated from $100 \%$ eluent A to $100 \%$ eluent B for $20 \mathrm{~min}$, where eluent $\mathrm{A}$ was $60 \% \mathrm{ACN}$ and eluent $\mathrm{B}$ $100 \%$ ACN.

Varian SPE manual system was used for preconcentration. Samples were pumped through cartridges with peristaltic pump model MS-4 REGLO (Ismatec, Switzerland).

During the derivatization step, samples were heated using thermoblock RM-5 Labart (JW Electronic, Poland) equipped with thermostatically controlled heating. 
Solid phase extraction procedures

PFCAs were preconcentrated using Oasis-WAX (30, 60 and $120 \mathrm{mg}, 30 \mu \mathrm{m})$ and Sep-Pak C18 (500 mg) cartridges purchased from Waters (Miliford, USA). Procedures with some modifications for Sep-Pak C18 were based on those described previously [16]. The Sep-Pak C18 cartridges were preconditioned with methanol $(5 \mathrm{~mL})$ followed by water $(2 \mathrm{~mL})$. Then standards solutions of PFCAs in water or natural water sample were passed through the cartridge with flow-rate $1 \mathrm{~mL} \mathrm{~min}{ }^{-1}$. After $15 \mathrm{~min}$ air drying, retained analytes were eluted with methanol (three $2.5 \mathrm{~mL}$ fractions). Each fraction was collected separately and evaporated under argon to dryness and next the residue dissolved in $2.5 \mathrm{~mL}$ or $1.0 \mathrm{~mL}$ of acetonitrile. The derivatization with coumarin derivatives proceeds better in acetonitrile than in methanol, but for elution methanol is preferred, so the evaporation and dissolving in acetonitrile was necessary.

For preconcentration with Oasis WAX cartridges, procedure presented by Tanyasu et al. [18] was applied. The cartridges were preconditioned with methanol containing 0.1 or $5 \%$ ammonia $(4 \mathrm{~mL})$ followed by methanol $(4 \mathrm{~mL})$ and water $(4 \mathrm{~mL})$. Then standard solutions of PFCAs in water were passed through the cartridge with flow-rate $1 \mathrm{~mL} \mathrm{~min}^{-1}$. After 15 min air drying, the target analytes were eluted with methanol containing 0.1 or $5 \%$ ammonia (three $4.0 \mathrm{~mL}$ fractions). Each fraction was collected separately and evaporated under argon to dryness and next the residue dissolved in $2.5 \mathrm{~mL}$ or $1.0 \mathrm{~mL}$ of acetonitrile. Such obtained solutions were derivatized with coumarin derivatives.

In recovery study, 25, 250 and $1,000 \mathrm{~mL}$ solutions of concentrations $30,3.0$ and $0.3 \mu \mathrm{g} \mathrm{L}^{-1}$, respectively, were preconcentrated. The final volumes of preconcentrated samples were 2.5, 2.5 and $1.0 \mathrm{~mL}$ and the preconcentration factors 10,100 and 1,000 were achieved.

\section{Derivatization procedure}

PFCA standard solutions or extracts in acetonitrile were mixed with solution of coumarin derivatives $(1: 1, \mathrm{v} / \mathrm{v})$ and heated in thermoblock in temperature $70{ }^{\circ} \mathrm{C}$ in closed, darkglass vials. Then after cooling, the obtained mixture was injected into HPLC system.

The reaction is inhibited by water hence using of dry vials and drying of cartridges after preconcentration is indispensable.

Analysis of surface water samples

Samples of natural surface waters were collected from various points in vicinity of chemical plant producing fluorinated polymers in town Tarnów, Sothern Poland. As PFCAs may strongly adsorb on the glass surface, water samples were collected in polyethylene containers washed with methanol [26]. Samples were stored without preservation at $4{ }^{\circ} \mathrm{C}$. Care was taken to avoid samples contact with PTFE.

Three $100 \mathrm{~mL}$ water samples were preconcentrated on SepPak C18 columns with flow rate $1 \mathrm{~mL} \mathrm{~min}{ }^{-1}$. Analytes were eluted with $5 \mathrm{~mL}$ methanol and evaporated in argon atmosphere. Solid residues was dissolved in $1 \mathrm{~mL} \mathrm{ACN}$, and $0.7 \mathrm{~mL}$ solution was used for $1 \mathrm{~h}$ derivatization at $70{ }^{\circ} \mathrm{C}$ with $2 \mathrm{gL}^{-1}$ solution of 3-BrAC.

A
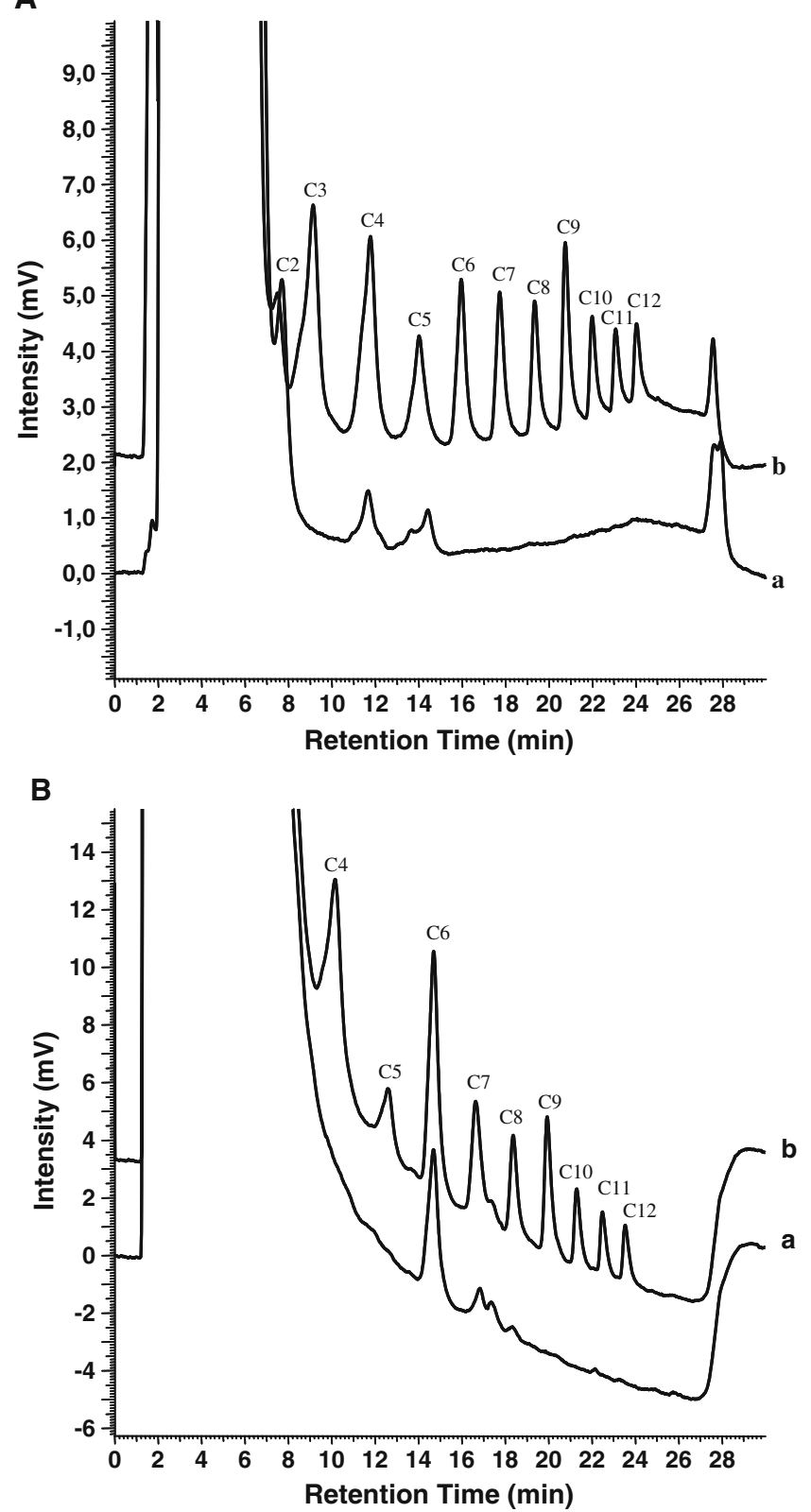

Fig. 1 Chromatograms obtained for blanks (a) and mixtures of $0.5 \mathrm{mg} \mathrm{L}^{-1}$ PFCA standards (b) for derivatization using $2 \mathrm{gL}^{-1}$ solution of 3-BrAC (A) and $2 \mathrm{gL}^{-1}$ solution of BrMMC. (B) Detection at $306 / 420 \mathrm{~nm}$ for $3-\mathrm{BrAC}$ and $330 / 390 \mathrm{~nm}$ for BrMMC 
A
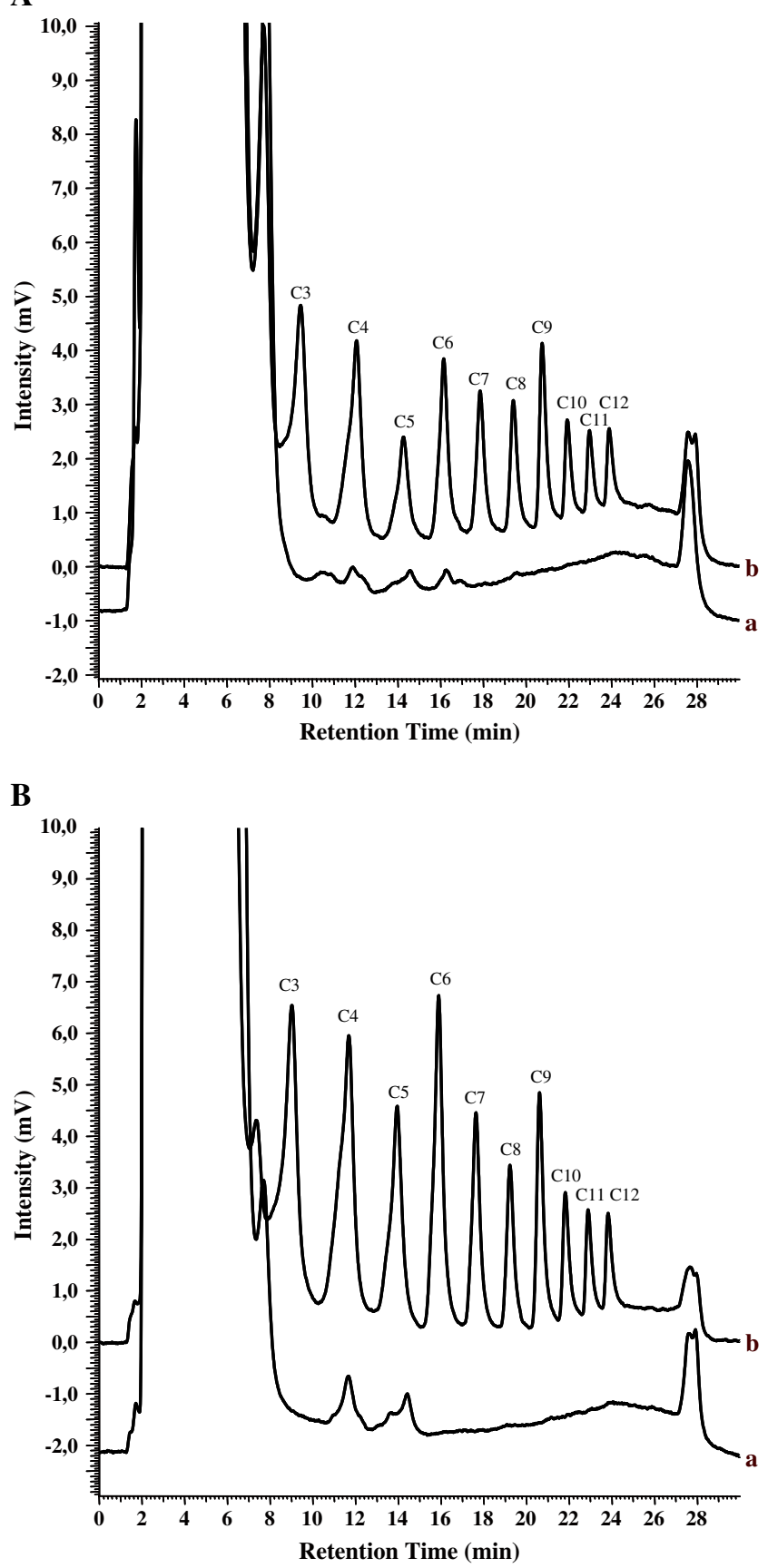

Fig. 2 Chromatograms obtained for blanks (a) and mixture of $0.5 \mathrm{mg} \mathrm{L}^{-1}$ PFCA standards (b) for derivatization with $2 \mathrm{gL}^{-1}$ (A) and $5 \mathrm{gL}^{-1}$ (B) solutions of $3-\mathrm{BrAC}$

Analysis of commercial preparations for shoe impregnation

Two commercial preparation were analyzed, aerosol from Kiwi, and liquid preparation from Boreal (Spain). Sample of aerosol $(282.2 \mathrm{mg})$ was weighted in hermetically closed vessel, and then dissolved in acetonitrile $(10 \mathrm{~mL})$, whereas sample of liquid preparation was 100 -fold diluted with acetonitrile. The $1 \mathrm{~mL}$ of acetonitrile solutions were taken for the derivatization.

\section{Results and discussion}

Optimization of derivatization procedure

Among numerous reagents used in derivatization for application of fluorescence detection in HPLC, coumarin derivatives belong to the most sensitive fluorophores. As it was mentioned above they have been already widely employed for derivatization of carboxylic acids, which are non or slightly UV adsorbing hence fluorescence derivatization is often used to their determination. So far, one such attempt was published in the literature on application for HPLC of perfluorinated carboxylic acids, where laboratory synthesized 3-bromoacetyl-7-methoxycoumarin was employed, and limit of detection was given as $50 \mathrm{pM} / 50 \mathrm{mg}$ of analyzed rat liver [18].

The yield of derivatization with coumarin derivatives, limit of detection and efficiency of separation of derivatized

A

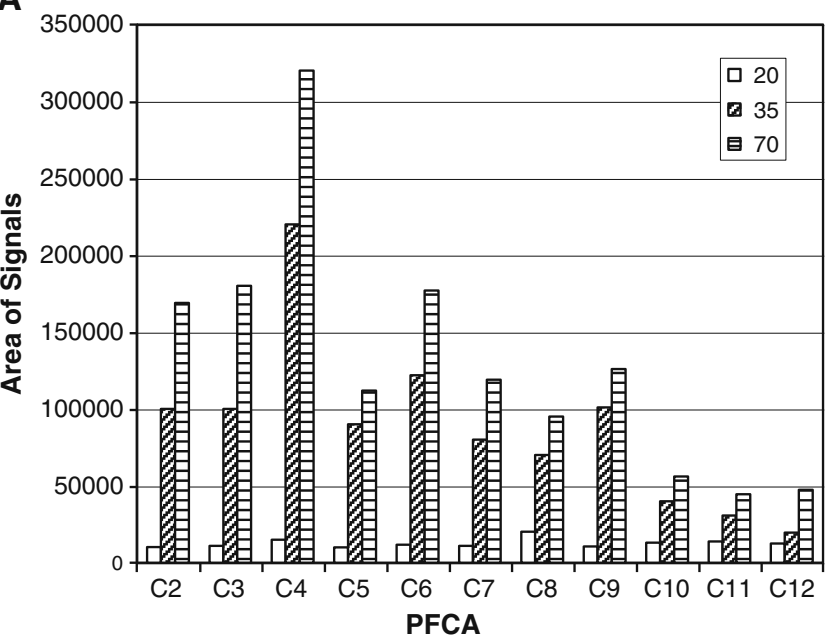

B

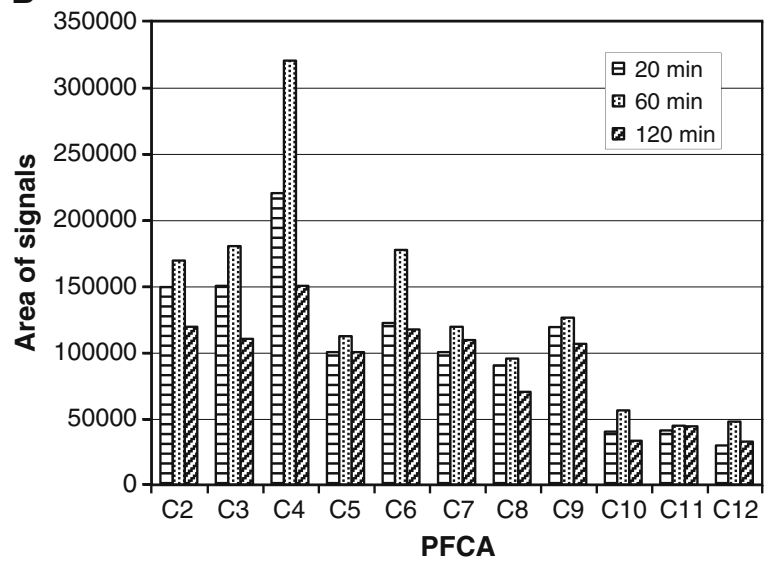

Fig. 3 Effect of temperature of derivatization (A) and derivatization time (B) on signal magnitude for derivatization with $2 \mathrm{gL}^{-1} 3-\mathrm{BrAC}$ solution for mixture of $0.3 \mathrm{mg} \mathrm{L}^{-1}$ PFCA standards 


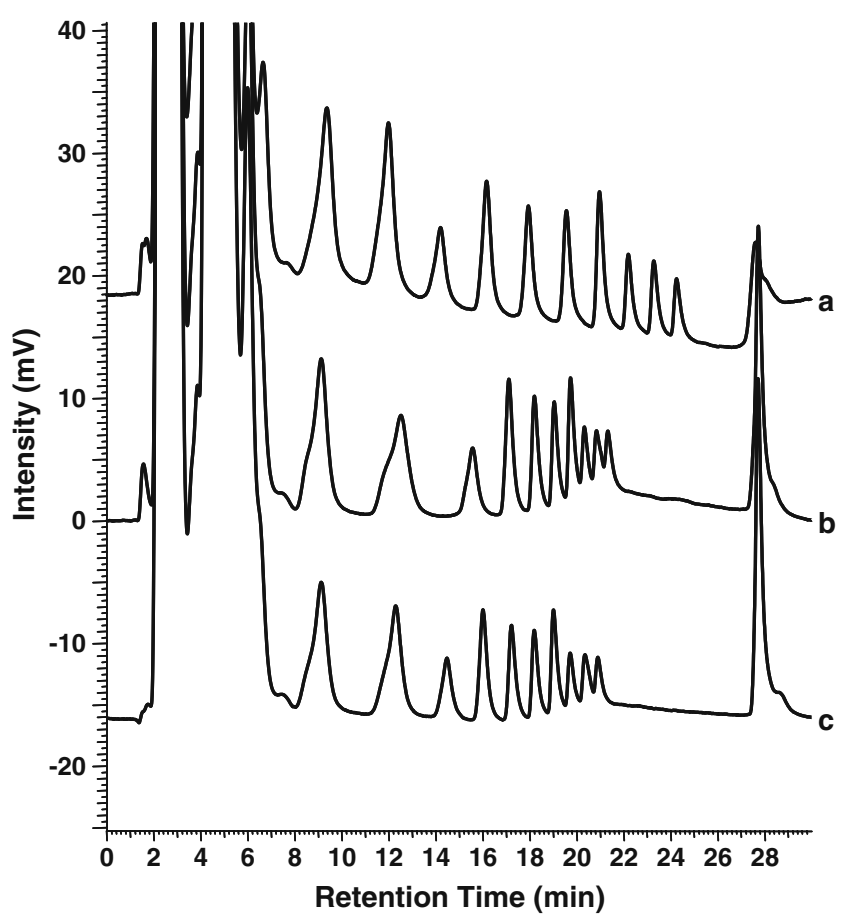

Fig. 4 Chromatograms obtained for mixture of $0.5 \mathrm{mg} \mathrm{L}^{-1}$ PFCA standards derivatized with $2 \mathrm{gL}^{-1}$ solution of 3-BrAC employing different gradient elutions (see text for details). Gradient (a) was assumed as optimum

analytes depend on numerous experimental factors [21-24]. In this study two different commercially available coumarin derivatives were examined as derivatization reagents for PFCAs, namely 3-BrAC and BrMMC. Using standard mixture containing PFCAs from $\mathrm{C} 2$ to $\mathrm{C} 12$ at $0.5 \mathrm{mg} \mathrm{L}^{-1}$ concentration each, for both derivatives effect of reagent concentration used for derivatization, reaction time, temperature of reaction and kind of solvent were examined.

Comparison of two reagents used for derivatization was made in $70{ }^{\circ} \mathrm{C}$, for reaction time $60 \mathrm{~min}$ and concentration of reagents $2 \mathrm{gL}^{-1}$. The obtained chromato- grams with corresponding recordings for blanks are shown in Fig. 1. In similar period of time about $25 \mathrm{~min}$ a better separation of all analytes and more stable base-line was obtained for samples derivatized with 3-BrAC. Surface areas for recorded peaks with two coumarin derivatives are very similar. Much larger signal for excess of reagent recorded for BrMMC makes impossible the recording of signals corresponding to $\mathrm{C} 2$ and C3-PFCA. A much larger signal recorded for C6-PFCA with BrMMC is caused by unidentified solutes present in blank. For further investigations 3-BrAC was selected as the derivatizing reagent.

The signal magnitude for derivatized PFCAs depends to some degree on concentration of 3-BrAC taken for derivatization, which was examined for 2 and $5 \mathrm{gL}^{-1}$ concentration. As one can see from recorded chromatograms (Fig. 2), about double increase of the signal magnitude for larger concentration of coumarin reagent is observed, which is however associated with larger signals for blank. For further studies $2 \mathrm{gL}^{-1}$ concentration was used.

The effect of temperature used in derivatization reaction is illustrated by the histogram in Fig. 3A showing data obtained in the temperature range from 20 to $70{ }^{\circ} \mathrm{C}$, for reaction time $60 \mathrm{~min}$. Its significant influence is evident for all examined analytes. At the highest examined temperature of derivatization $70{ }^{\circ} \mathrm{C}$ also effect of derivatization time was investigated in the range from 20 to $120 \mathrm{~min}$ (Fig. 3B). The role of this parameter is smaller, and the decrease of signal magnitude at $120 \mathrm{~min}$ for most analytes was attributed to the loss of analytes during long time derivatization. As some loss of more volatile species can be expected also at highest examined temperature, as the most safe and efficient conditions of derivatization were selected 60 min derivatization at $70{ }^{\circ} \mathrm{C}$.

Due to large differences in affinity of examined analytes to C18 stationary phase in reversed-phase system, their
Table 1 Values of retention time, regression equations, correlation coefficients for linear calibration plots, and limits of detection obtained for examined PFCAs in reversed-phase HPLC determination with fluorescence detection employing derivatization with 3-BrAC (without additional preconcentration)

\begin{tabular}{lcccc}
\hline PFCA & Retention time $(\mathrm{min})$ & Regression equations & Correlation coefficient & LOD $\left(\mu \mathrm{g} \cdot \mathrm{l}^{-1}\right)$ \\
\hline $\mathrm{C} 2$ & 6.5 & $\mathrm{y}=336356 \mathrm{x}$ & 0.9997 & 7.5 \\
$\mathrm{C} 3$ & 9.1 & $\mathrm{y}=356820 \mathrm{x}$ & 0.9998 & 5.5 \\
$\mathrm{C} 4$ & 11.3 & $\mathrm{y}=640191 \mathrm{x}$ & 0.9997 & 6.0 \\
$\mathrm{C} 5$ & 13.3 & $\mathrm{y}=224169 \mathrm{x}$ & 0.9996 & 6.8 \\
$\mathrm{C} 6$ & 15.0 & $\mathrm{y}=354849 \mathrm{x}$ & 0.9995 & 6.5 \\
C7 & 16.5 & $\mathrm{y}=222639 \mathrm{x}$ & 0.9997 & 6.6 \\
C8 & 17.9 & $\mathrm{y}=190238 \mathrm{x}$ & 0.9998 & 4.6 \\
C9 & 19.1 & $\mathrm{y}=251250 \mathrm{x}$ & 0.9998 & 4.3 \\
C10 & 20.2 & $\mathrm{y}=111682 \mathrm{x}$ & 0.9997 & 6.8 \\
C11 & 21.1 & $\mathrm{y}=88769 \mathrm{x}$ & 0.9995 & 6.5 \\
C12 & 22.0 & $\mathrm{y}=95421 \mathrm{x}$ & 0.9998 & 7.5 \\
\hline
\end{tabular}




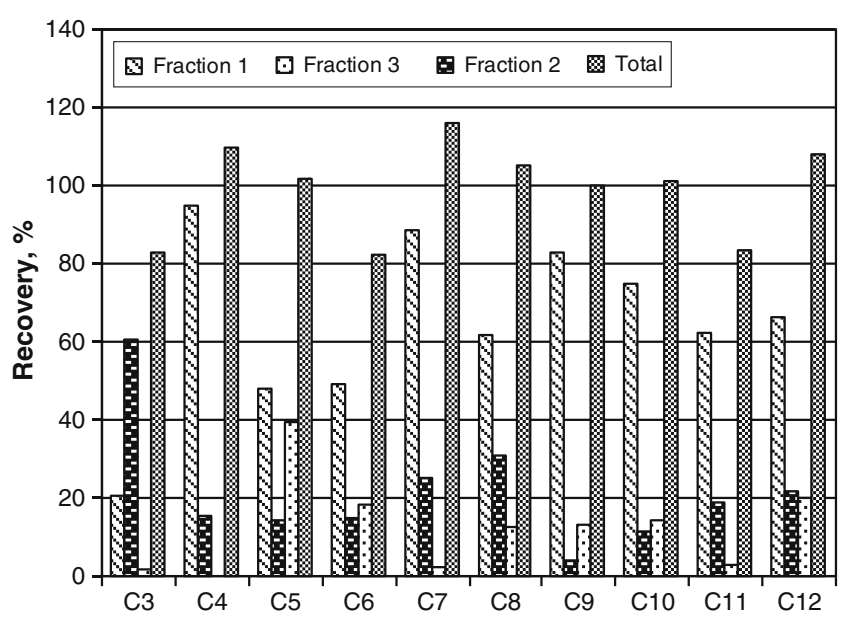

Fig. 5 Comparison of recoveries obtained for elution with three consecutive fractions of $2.5 \mathrm{~mL}$ methanol and total recovery from all fractions for 100-fold preconcentration of PFCAs from $250 \mathrm{~mL}$ solution containing $3.0 \mu \mathrm{g} \mathrm{L}^{-1}$ each analyte. Preconcentration carried out on $500 \mathrm{mg}$ Sep-Pak C18 sorbent bed

efficient separation in reasonable time period can be obtained for gradient elution, only. The additional factor that should be considered is the elimination of possible overlapping of signals for analytes with excess of reagent used for derivatization. For separation of mixture of PFCAs from $\mathrm{C} 2$ to $\mathrm{C} 12$ three different gradient programs were investigated, using $60 \%$ aqueous solution of $\mathrm{ACN}(\mathrm{A})$ and pure ACN (B). Initially, isocratic elution with eluent A during 5 min (Fig. 4a), 6 min (Fig. 4b) and 4 min (Fig. 4c) was used. Next linear gradient elution from 5 to $20 \mathrm{~min}$ (Fig. 4a), 6-18 min (Fig. 4b) and 4-15 min (Fig. 4c) was applied. As it is demonstrated by recorded chromatograms shown in Fig. 4 program (a) can be considered as the most appropriate.

Figures of merit of developed method

In optimized conditions of derivatization the determinations of PFCAs were carried out in concentration range from 0.025 to $0.5 \mathrm{mg} \mathrm{L}^{-1}$ in injected solutions. For $50 \mu \mathrm{L}$ sample volume satisfactory linearity of response was obtained and limits of detection (for $\mathrm{S} / N=3$ ) in the range from 5 to $10 \mu \mathrm{g} \mathrm{L}^{-1}$ (Table 1).

In the study of repeatability of derivatization procedure with $3-\mathrm{BrAC}$ in optimized conditions, for 5 repetitions carried out in 5 consecutive days, RSD values for peak areas for all analytes were below $1 \%$. No significant differences in the efficiency of the separation were also observed. Derivatized analytes were stable in time, as after 2 days of storage recorded chromatograms were practically the same as those recorded immediately after derivatization. No additional by-products after 2 days storage were observed.

\section{Optimization of SPE preconcentration procedure}

The detection limits obtained in developed procedure are too high for direct determination of PFCAs at level present

A

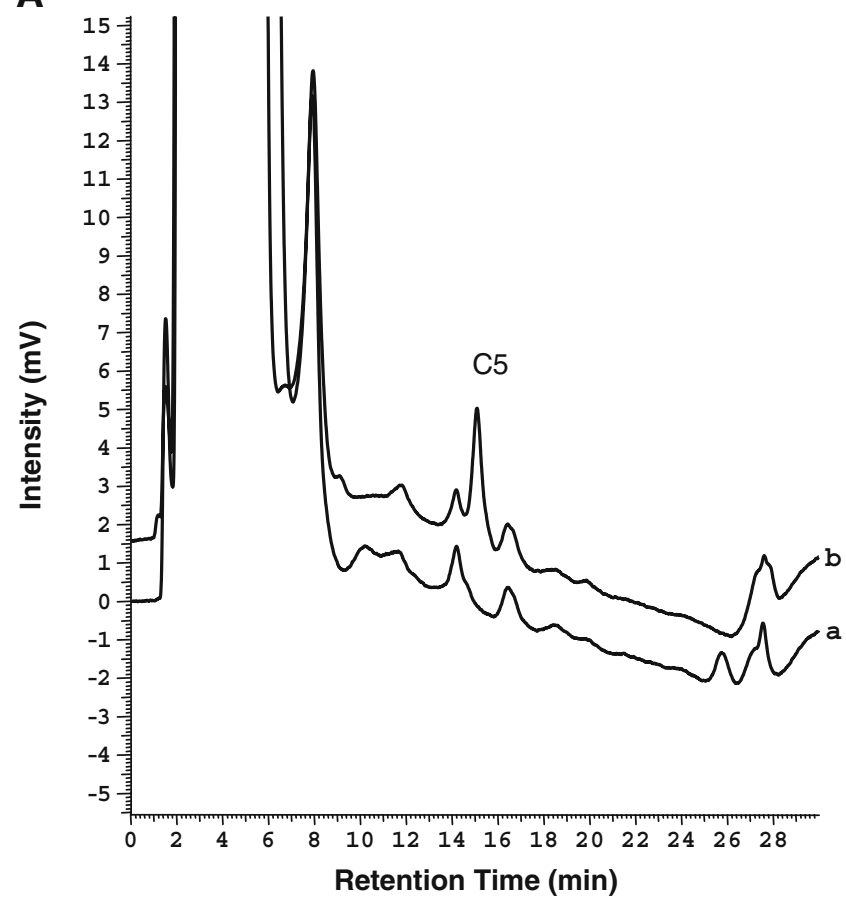

B

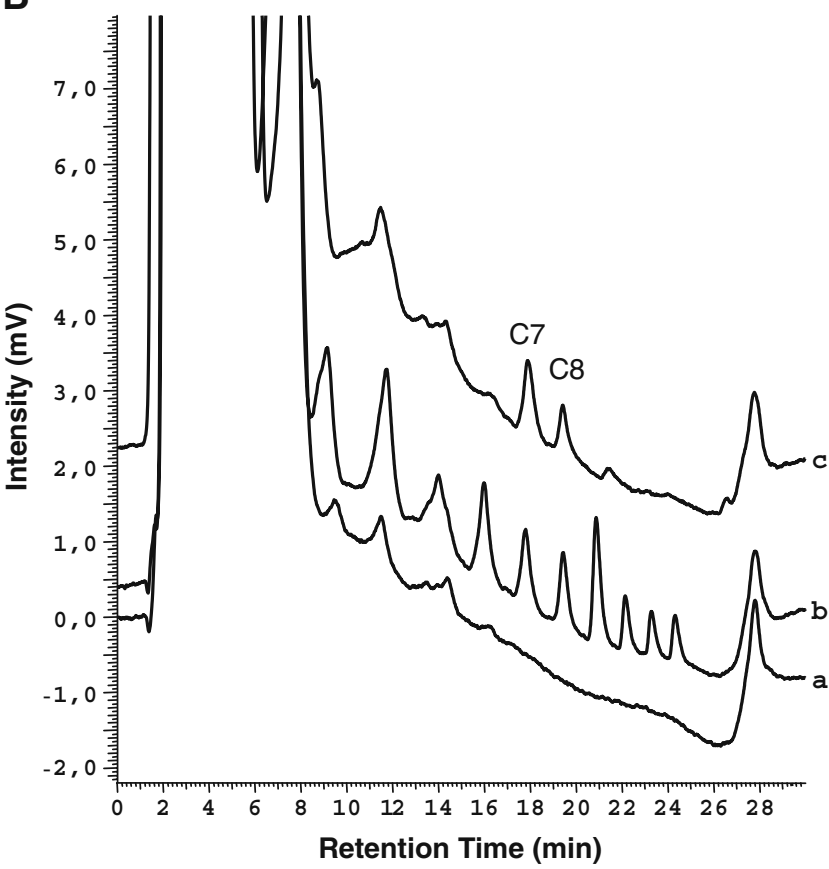

Fig. 6 Chromatograms obtained for Boreal shoe preparation (A): ablank, b-sample, and natural water sample after 100-fold preconcentration (B): a-blank, b-0.1 $\mathrm{mg} \mathrm{L}^{-1}$ standard solution (without preconcentration), c-sample 
in natural waters $[16,25]$. As this application is one of the targets of this work, the next step in development of the complete procedure was the optimization of the solid-phase extraction method for the preconcentration of analytes from diluted natural samples. Based on vast literature on the application of different sorbents for this purpose [26], two commercially available sorbents were selected for this purpose: Sep-PAK C18 and Oasis-WAX. Besides the optimization of elution mode for retained species on the sorbent bed, another essential factor was to eliminate traces of water from extracts, which interferes in derivatization reaction.

For sorbent Sep-PAK C18 optimum pH range is from 3 to 7 and it can be used for preconcentration of hydrophobic solutes. Mixtures of PFCAs containing 30, 3.0 or $0.3 \mu \mathrm{g} \mathrm{L}^{-1}$ each were preconcentrated from sample volumes 25,250 and $1,000 \mathrm{~mL}$, respectively, in order to obtain well measurable amounts of analytes in the final extract, to examine the recovery of preconcentration. The derivatization with coumarin derivatives proceeds with larger yield in acetonitrile than in methanol, hence in the first attempt ACN was tested as eluent of retained analytes, however for this solvent much lower recoveries were observed than for methanol. In alternative procedure, elution was carried out with methanol, which then was evaporated in the argon stream, and solid residue was dissolved in ACN for further derivatization.

Because of strong retention of examined analytes on $\mathrm{C} 18$ sorbent bed, the recovery of elution was investigated using three $2.5 \mathrm{~mL}$ fractions of methanol. The obtained data for 100-fold preconcentration using $500 \mathrm{mg}$ sorbent bed are shown in Fig. 5. The satisfactory recovery (above 80\%) with single portion of methanol was obtained for $\mathrm{C} 4, \mathrm{C} 7$ and C9 PFCAs, only. All data represents mean of 3 parallel measurements. The total recovery obtained by means of three fractions of eluting methanol was satisfactory for all examined analytes from $\mathrm{C} 3$ to $\mathrm{C} 12$ PFCA, except $\mathrm{C} 2$ where much lower total recovery was found. The reproducibility of this procedure was also satisfactory, as the RSD was obtained for various analytes in the range from 0.2 to $1.4 \%$.
For 1000-fold preconcentration from $1 \mathrm{~L}$ sample containing $0.3 \mathrm{mg} \mathrm{L}^{-1}$ of each PFCA, satisfactory total recovery above $90 \%$ was obtained for C4 to C6 PFCAs, only, whereas for other examined analytes it was much lower, and nonacceptable for practical applications.

Similar studies were carried out also for Oasis-WAX cartridges. As according to manufacturer this sorbent can be used for partly polar analytes with $\mathrm{pK}_{\mathrm{a}}$ values about or larger than 1.0, it seems to be suitable for examined analytes, where retention is based on both hydrophobic and ion-exchange interactions. Investigation of the role of amount of sorbent taken for preconcentration and level of ammonia in methanol was investigated, however, a satisfactory elution (recovery better than $80 \%$ ) was observed for few PFCAs, only, namely C4, C5, C6 and C9. Amount of sorbent used for preconcentration affects obtained recovery but in used conditions where 100-fold preconcentration was carried out from $250 \mathrm{~mL}$ samples containing $3 \mu \mathrm{g} \mathrm{L} \mathrm{L}^{-1}$ of each PFCA doubling amount of sorbent from 60 to $120 \mathrm{mg}$ did not affect recovery of analytes. Elution with three consecutive portions of $4.0 \mathrm{~mL}$ methanol containing ammonia for 100 -fold preconcentration, also does not improve total recovery. Based on obtained experimental data C18 sorbent Sep-PAK was considered as more suitable for the preconcentration of trace amounts of PFCA from environmental samples.

\section{Analytical applications of developed method}

Two different examples were examined to illustrate the possible applications of the developed method. In the first one, PFCAs content was measured in two preparations for shoe impregnation, which did not require preconcentration step. Following the procedure given in Experimental, in acetonitrile solution obtained from aerosol preparation Kiwi, three PFCAs have been determined, namely C3, C8 and C9 PFCA at level $0.137,0.107$ and $0.215 \mathrm{mg} \mathrm{L}^{-1}$, which corresponds to $4.85,3.79$ and $7.62 \mathrm{mg} \mathrm{g}^{-1}$ of analyzed samples. In liquid preparation Boreal, only C5-PFCA was

Table 2 Comparison of different chromatographic methods reported in the literature for determination of PFCAs

\begin{tabular}{|c|c|c|c|}
\hline Method & Sample & LOD & Reference \\
\hline GC-MS & Harbor seawater Waste water & $\begin{array}{l}0.02-0.75 \mu \mathrm{g} \mathrm{L}^{-1} \text { (with SPME preconcentration } \\
\text { from } 5 \mathrm{~mL} \text { samples) }\end{array}$ & {$[27]$} \\
\hline HPLC with conductivity detection & Industrial process liquids & $\begin{array}{l}0.12-0.66 \mathrm{mg} \mathrm{L}^{-1} \text { and } 50 \mu \mathrm{g} \mathrm{L}^{-1} \text { (with SPE } \\
\text { preconcentration from } 100 \mathrm{~mL} \text { samples) }\end{array}$ & {$[15]$} \\
\hline HPLC with fluorescence detection & Liver homogenate & $50 \mathrm{pmol} / 50 \mathrm{mg}$ tissue & [18] \\
\hline LC-MS/MS & Seawater & 1.8-5.2 $\mathrm{pg} \mathrm{L}^{-1}$ (with SPE from $1 \mathrm{~L}$ sample) & [9] \\
\hline HPLC with fluorescence detection & Surface water & $\begin{array}{l}43-75 \mathrm{ng} \mathrm{L}^{-1} \text { (with SPE preconcentration } \\
\text { from } 100 \mathrm{~mL} \text { samples) }\end{array}$ & This work \\
\hline
\end{tabular}

SPE solid-phase extraction; SPME solid-phase micro extraction 
determined at $0.85 \mathrm{mg} \mathrm{L}^{-1}$ level. The example recorded chromatogram for analyzed samples is shown in Fig. 6A.

A complete procedure with 100 -fold preconcentration with C18 Sep-PAK $500 \mathrm{mg}$ cartridge was employed for determination of PFCAs in surface water sample collected from industrial region close to Tarnów city in Southern Poland. Chromatograms recorded for blank, standard mixture of PFCAs, and analyzed sample are shown in Fig. 6B. Based on retention times, two PFCA analytes were identified, namely $\mathrm{C} 7$ and C8 (PFOA) at concentrations $1.0,0.63 \mathrm{ppb}$, respectively. Recoveries $93.2 \%$ and $99.3 \%$ for $\mathrm{C} 7$ and $\mathrm{C} 8$ in natural water were obtained.

\section{Conclusions}

The environmental importance of perfluorinated organic compounds widely discussed in recent decade requires a continuous improvement of the analytical methods for routine use. Although they are commonly determined in advanced analytical laboratories by LC/MS with satisfactory selectivity and limits of detection, there is also a need for methods suitable for more common use in e.g. local environmental laboratories. Such a role can be played by the reversed-phase HPLC method with fluorescence detection developed in this work, which is demonstrated for the determination of PFCAs, a widely proliferated group of perfluorinated organic compounds. The application of commercial derivative of coumarin allows relatively simple derivatization with well repeatable formation of derivatized products. Developed gradient method of elution allows efficient separation of whole range of PFCAs from $\mathrm{C} 3$ to $\mathrm{C} 12$. With obtained limits of detection in the range from 4.3 to $7.5 \mathrm{ppb}$ it can be used for the control of content of these species in household preparations or cosmetics.

Applications in environmental analysis e.g. for surface water analysis require additional preconcentration of trace analytes. Satisfactory results were obtained with 100 -fold preconcentration using commercial solid-phase extraction cartridges C18 Sep-PAK, with recoveries at least $80 \%$. This allows obtaining LODs values in the range $43-75 \mathrm{ppt}$, which is satisfactory for environmental applications for monitoring of these analytes. In comparison to the previous work on application of HPLC with fluorimetric detection for analysis of rats liver samples [18], in this work the commercial derivatizing reagent was employed and developed method was optimized for trace analysis of environmental samples. Taking into account of a current wide demand for monitoring of perfluorinated compounds in environmental samples, the developed method can be the easier available alternative compared to costly and required highly trained personnel LC/MS methods for routine environmental applications.
As it is shown by comparison of LOD values reported for different chromatographic methods (Table 2), only application of LC/MS allows the obtained better limits of detection, however LC/MS instrumentation still is too expensive for common application in environmental monitoring. The LOD values obtained in this work illustrate its possible application in routine environmental analysis for PFCA determination [17] with use of much simpler and more commonly employed instruments. Such possibility was not so far investigated with HPLC using fluorescence detection for environmental samples. Similar method with different fluorophore was developed only for analysis of biological material [18].

Acknowledgements The authors thank Dr. Bogdan Szostek (E.I. DuPont De Nemours \& Co. Inc., Wilmington, DE, USA) for his advice and assistance during the conduct of experiments and manuscript preparation. We acknowledge also financial support from DuPont's Center for Collaborative Research and Education, Europe under the European University Support Program.

Open Access This article is distributed under the terms of the Creative Commons Attribution Noncommercial License which permits any noncommercial use, distribution, and reproduction in any medium, provided the original author(s) and source are credited.

\section{References}

1. Kissa E (2001) Fluorinated surfactants and repellents, 2nd edn. Marcel Dekker Inc., New York

2. Houde M, Martin JW, Letcher RJ, Solomon KR, Muir DCG (2006) Biological monitoring of perfluoroalkyl substances: a review. Environ Sci Technol 40:3463-3470

3. Ellis AD, Martin J, De Silva AO, Hurley MD, Mabury SA, Sulbaek-Andersen MP, Wallington TJ (2004) Degradation of fluorotelomer alcohols: a likely atmospheric source of perfluorinated carboxylic acids. Environ Sci Technol 38:3316-3321

4. Giesy JP, Kannan K (2001) Global distribution of perfluorooctane sulfonate in wildlife. Environ Sci Technol 35:1339-1342

5. Hansen KJ, Clement LA, Ellefsen ME, Johnson HO (2001) Compound-specific quantitative characterization of organic fluorochemicals in biological matrices. Environ Sci Technol 35:766-770

6. Prevedouros K, Cousins IT, Buck RC, Korzeniowski SH (2006) Sources, fate and transport of perflurocarboxylates. Environ Sci Technol 40:32-40

7. Andersen MA, Butenhoff JL, Chang SC, Farrar DG, Kennedy GL, Lau C, Olsen GW, Seed J, Wallace KB (2008) Perfluoroalkyl acids and related chemistries - toxokinetics and modes of action. Toxicol Sci 102:3-14

8. Martin JW, Kannan K, Berger U, De Voogt P, Field J, Franklin J, Giesy JP, Harner T, Muir DCG, Scott B, Kaiser M, Järnberg U, Jones KC, Mabury SA, Schroeder H, Simcik M, Sottani C, Van Bavel B, Kärrman A, Lindström G, Van Leeuwen S (2004) Analytical challenges hamper perfluoroalkyl research. Environ Sci Technol 38:248A-255A

9. Yamashita N, Kannan K, Taniyasu S, Horii Y, Okazawa T, Petrick G, Gamo T (2004) Analysis of perfluorinated acids at parts-perquadrillion levels in seawater using liquid chromatographytandem mass spectrometry. Environ Sci Technol 38:5522-5528 
10. Powley CR, George SW, Ryan TW, Buck RC (2005) Matrix effectfree analytical methods for determination of perfluorinated carboxylic acids in environmental matrixes. Anal Chem 77:6353-6358

11. Washington JW, Henderson WM, Ellington JJ, Jenkins TM, Evans JJ (2008) Analysis of perfluorinated carboxylic acids in soils II: optimization of chromatography and extraction. J Chromatogr A 1181:21-32

12. Kannan K, Corsolini S, Falandysz J, Oehme G, Focardi S, Giesy JP (2002) Perfluorooctanesulfonate and related fluorinated hydrocarbons in marine mammals, fishes, and birds from coasts of the Baltic and the Mediterrean sweas. Environ Sci Technol 36:3210-3216

13. Butt CM, Mabury SA, Muir DCG, Braune BM (2007) Prevalence of long-chained perfluorinated carboxylates in seabirds from the Canadian Arctic between 1975 and 2004. Environ Sci Technol 41:3521-3528

14. Flaherty JM, Connolly PD, Decker ER, Kennedy SM, Ellefson ME, Reagen WK, Szostek B (2005) Quantitative determination of perfluorooctanoic acid in serum and plasma by liquid chromatography tandem mass spectrometry. J Chromatogr B 819:329-338

15. Hori H, Hayakawa E, Yamashita N, Taniyasu S, Nakata F, Kayabashi Y (2004) High-performance liquid chromatography with conductimietric detection of perfluorocarboxylic acids and perfluorosulfonates. Chemosphere 57:273-282

16. Moody CA, Kwan WC, Martin JW, Muir DCG, Mabury SA (2001) Determination of perfluorinated surfactants in surface water samples by two independent analytical techniques: liquid chromatography/ tandem mass spectrometry and ${ }^{19} \mathrm{~F}$ NMR. Anal Chem 73:2200-2206

17. Maclachlan MS, Holmstrom KE, Reth M, Berger U (2007) Riverine discharge of perfluorinated carboxylates from the European continent. Environ Sci Technol 41:7260-7265

18. Ohya T, Kudo N, Suzuki E, Kawashima Y (1998) Determination of perfluorinated carboxylic acids in biological samples by highperformance liquid chromatography. J Chromatogr B 720:1-7
19. Kudo E, Katakura M, Sato Y, Kawashima Y (2002) Sex hormoneregulated renal transport of perfluorooctanoic acid. Chem-Biol Interact 139:301-316

20. Ohmori K, Kudo N, Katayama K, Kawashima Y (2003) Comparison of the toxicokinetics between perfluorocarboxylic acids with different carbon chain length. Toxicology 184:135-140

21. Dunges W (1977) 4-Bromomethyl-7-methoxycoumarin as a new fluorescence label for fatty acids. Anal Chem 49:442-445

22. Peris Vicente J, Gimeno Adelantado JV, Domenech Carbo MT, Mateo Castro R, Bosch Reig F (2005) Identification of lipid binders in old oil paintings by separation of 4-bromomethyl-7-methoxycoumarin derivatives of fatty acids by liquid chromatography with fluorescence detection. J Chromatogr A 1076:44-50

23. Shen JL, Hummert C, Luckas B (1997) Sensitive HPLC-fluorometric and HPLC-MS determination of diarrhetic poisoning (DSP)-toxins as 4-bromomethyl-7-methoxy-coumaric esters. Fresenius J Anal Chem 357:101-104

24. Xie ZM, Shi WB, Liu L, Deng QD (2007) Determination of sodium monofluoroacetate in biological samples as its 4-bromo-7methoxycoumarin derivative by RP-HPLC. J Chromatogr Sci 45:405-408

25. Arens L, Plassmann M, Xie Z, Ebinghaus R (2009) Determination of polyfluoroalkyl compounds in water and suspended particulate matter in the river Elbe and North Sea, Germany. Front Environ Sci Engin China 3:152-170

26. Van Leeuwen SPJ, De Boer J (2007) Extraction and clean-up strategies for the analysis of poly- and perfluoroalkyl substances in environmental and human matrices. J Chromatogr A 1153:172185

27. Alzaga R, Bayona JM (2004) Determination of perfluorocarboxilic acids in aqueous matrices by ion-pairing solid-phase microextractionin-port derivatization-gas chromatography-negative ion chemical ionization mass spectrometry. J Chromatogr A 1042:155-162 